\title{
Electrolytic Polymerization of Tetrahydrofuran
}

\author{
Seiichi Nakahama, Seiichi Hino, and Noboru Yamazaki \\ Tokyo Institute of Technology, Ohokayama, Meguro-ku, Tokyo, Japan.
}

(Received September 2, 1970)

\begin{abstract}
The electrolytic polymerization of tetrahydrofuran (THF) was carried out in bulk by using tetrabutylammonium perchlorate as an electrolyte. Poly-THF was obtained from the anolyte. The yield of the polymer increased with the reaction time and leveled off at about $70 \%$. The molecular weight of the polymer increased proportionally to the yield of the polymer as was observed in the living polymer system. About two moles of hydroxyl end group were determined per mole of the polymer. In the polarographic measurement, THF gives no oxidation wave. From the results obtained an initiation mechanism is proposed, involving the perchlorate radical and proton. The presence of radical species is indicated by the electrolytic copolymerization of methyl methacrylate and acrylonitrile.
\end{abstract}

KEY WORDS Electrolytic Polymerization/Tetrahydrofuran/Initiation/

Perchlorate Radical/Polytetrahydrofuran/

Although many reports on the electrolytic polymerization of vinyl monomers have been published, there have been few studies concerning ring-opening polymerization of cyclic monomers by the electrochemical process ${ }^{1}$. In respect of cyclic monomers, the electrolytic polymerization of tetrahydrofuran (THF) has been studied in our laboratory ${ }^{2}$ and by Heins, ${ }^{3}$ but the mechanism of the polymerization has not yet been clarified. We wish to report, in this paper, some results of the electrolytic polymerization of THF and discuss the mechanism of the reaction in detail.

\section{EXPERIMENTAL}

\section{Materials}

THF was dried over $\mathrm{LiAlH}_{4}$ and distilled.

Tetra- $n$-butylammonium perchlorate $\left(\mathrm{Bu}_{4} \mathrm{NCl}\right.$ $\mathrm{O}_{4}$ ) was synthesized from tetra- $n$-butylammonium iodide and sodium perchlorate and recrystallized from ethyl acetate.

\section{Electrolytic Polymerization}

Electrolysis was carried out at $0^{\circ} \mathrm{C}$ in the modified H-type glass cell as shown in Figure 1. The cell, which contained the supporting electrolyte, was dried thoroughly under vacuum $\left(<10^{-4} \mathrm{mmHg}\right)$ for about $10 \mathrm{hr}$ and THF was then introduced into the cell via the trap-to-trap method. After electrolysis, the anolyte A was

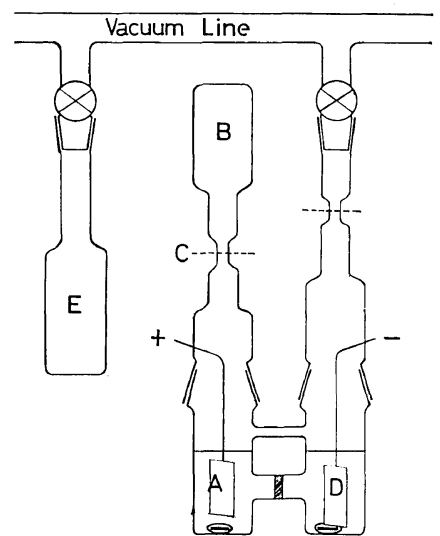

Figure 1. Electrolysis cell: A, anode; B, ampoule for polymerization; $C$, the ampoule was fused and cut off at C; D, cathode; E. THF monomer was dried with $\mathrm{LiAlH}_{4}$ in the tube $\mathrm{E}$ and transferred to the cell by the trap-to-trap method.

transferred into the glass ampoule $\mathrm{B}$, which was fused and cut off at C. For further polymerization, the ampoule, which contained the anolyte, was kept at $30^{\circ} \mathrm{C}$ in a thermostatic bath for the required time. The polymer was isolated by precipitation with excess water. A white solid was obtained by the freeze-drying. method from benzene solution.

Determination of Aldehyde Groups in Poly-THF

The polymer was precipitated with THF- 
Electrolytic Polymerization of Tetrahydrofuran

Table I. The electrolytic polymerization of tetrahydrofuran ${ }^{2}$

\begin{tabular}{|c|c|c|c|c|c|c|}
\hline No. & $\begin{array}{l}\text { THF in } \\
\text { feed, } g\end{array}$ & $\begin{array}{l}\text { Reaction } \\
\text { time, }{ }^{b} \mathrm{hr}\end{array}$ & $\begin{array}{l}\text { Yield, } \\
\%\end{array}$ & $\begin{array}{l}\text { Molecular weight } \\
\text { of polymerc }\end{array}$ & $\begin{array}{l}\text { Number of } \\
\text { polymer, }{ }^{\mathrm{m}} \text { mole }\end{array}$ & $\begin{array}{l}\text { Current effl- } \\
\text { ciency, }{ }^{\circ} \% f\end{array}$ \\
\hline 032 & 15.9 & 3 & 27 & $1.6 \times 10^{4}$ & $2.8 \times 10^{-4}$ & 24 \\
\hline 028 & 17.4 & 10 & 47 & 2.9 & 2.8 & 24 \\
\hline 023 & 19.9 & 20 & 58 & 4.1 & 2.8 & 24 \\
\hline 025 & 16.3 & 35 & 68 & 4.7 & 2.4 & 20 \\
\hline 021 & 17.9 & 260 & 70 & 5.1 & 2.4 & 20 \\
\hline
\end{tabular}

a Electrolysis conditions: cell voltage, $90-110 \mathrm{~V}$; current, $5-8 \mathrm{~mA}$; temp, $0^{\circ} \mathrm{C}$; amount of current, $1.2 \mathrm{mF}$; supporting electrolyte, $1.37 \mathrm{~g}$ of $\mathrm{Bu}_{4} \mathrm{NClO}_{4}$ for each run.

b Reaction time for the polymerization at $30^{\circ} \mathrm{C}$, excluding the time for electrolysis.

c Estimated from the gel-permeation chromatogram.

d Yield $/ M_{n}$

e $f=\left[\right.$ Yield $/ M_{n} /$ amount of current $] \times 100$

water system and was extracted in diethyl ether, which did not dissolve the suporting electrolyte, $\mathrm{Bu}_{4} \mathrm{NClO}_{4}$. After the electrolyte was filtered, ether was removed under reduced pressure from the filtrate. Finally the polymer was purified by the freeze-drying method from benzene solution. The poly-THF was dissolved in THF and excess of 2, 4-dinitrophenylhydrazine (DNPH) was added to the solution, which was kept overnight at room temperature. After completion of the reaction, the polymer was isolated by freeze-drying method. The weighed polymer, $40 \sim 100 \mathrm{mg}$, was dissolved in $5 \mathrm{ml}$ of THF and the solution was introduced into the column of the gel-permeation chromatograph. The gelpermeation chromatogram of the polymer and optical density of the eluted fractions were
Table II. The determination of hydroxyl groups in poly-THF produced by electrolytic polymerization $^{\mathrm{a}}$

\begin{tabular}{cccc}
\hline No. $\begin{array}{c}\text { Molecular weight } \\
\text { of polymer }\end{array}$ & $\begin{array}{c}\text { Content of hydroxyl groups, } \\
\text { (m equivhydroxyl/g) }\end{array}$ \\
\cline { 2 - 4 } & & Obsd & Calcd $^{\mathrm{b}}$ \\
\hline 7 & $1.28 \times 10^{4}$ & 0.18 & 0.16 \\
8 & $1.49 \times 10^{4}$ & 0.13 & 0.13
\end{tabular}

a The hydroxyl-containing polymer reacts with phosgene to form the chloroformate. After hydrolysis of the chloroformate, the chloride content, which is equivalent to the hydroxyl content, is titrated.

b Calculated on the assumption that each polymer has two hydroxyl groups at its terminals.

Table III. The determination of aldehyde groups in poly-THF produced by electrolytic polymerization ${ }^{a}$

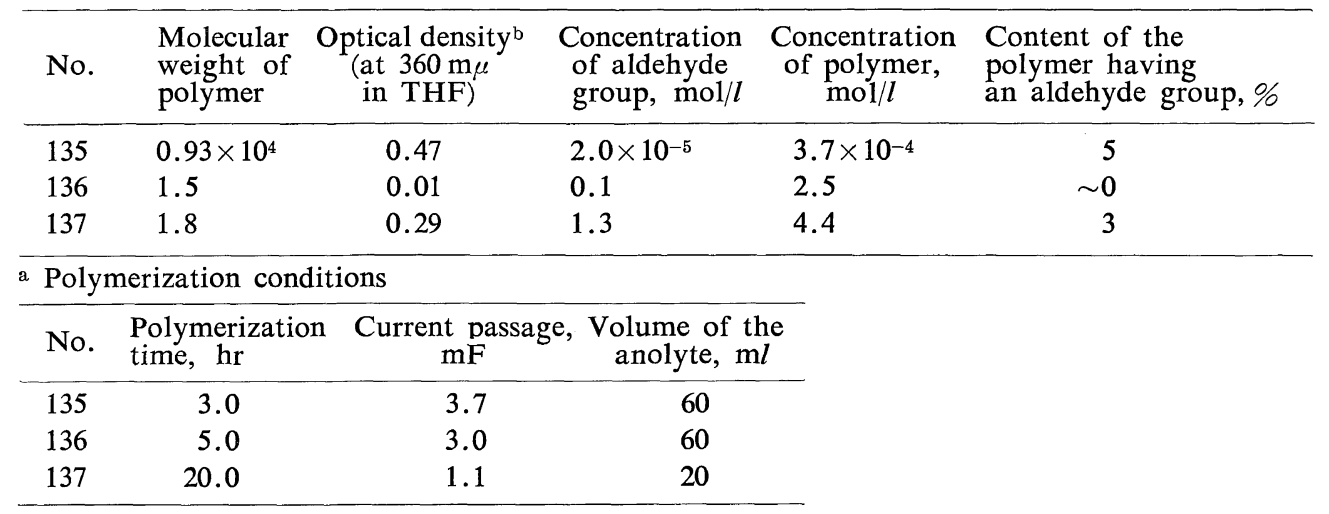

Other conditions are shown in Table I.

b Corrected values. 
measured. The typical curves are shown Figure 5. The calibration for the concentration of the hydrazone was made with DNPH and $n$-butyraldehyde in the range of $(1 \sim 8) \times 10^{-5} \mathrm{~mol} / l$. The measured values were corrected with the back ground absorption of the solution of the polymer which did not react with DNPH. As shown in Table III, the values were somewhat scattered. The experimental error might result chiefly from this correction and the conditions of polymerization did not seem to affect the measured value.

\section{RESULTS AND DISCUSSION}

During the electrolysis of $\mathrm{Bu}_{4} \mathrm{NClO}_{4}$ - THF solution, the anolyte became yellow and then gradually changed to dark brown, whereas no color change was observed for the catholyte. During the electrolysis at $0^{\circ} \mathrm{C}$, only a small amount of polymer was formed. The anolyte was kept in the ampoule at $30^{\circ} \mathrm{C}$, where the solution became viscous in a few hours.

Typical experimental results are shown in Table I. The yield of the polymer increased with the reaction time and leveled off at seventy percent. This suggests that the polymerization reached a monomer-polymer equilibrium as was reported by Dreyfuss, et al. ${ }^{4}$ As shown Figure 2, there is a linear relationship between the molecular weight and yield of the polymer. Consequently the number of the polymer, calculated from yield $/ \bar{M}_{n}$, is kept almost constant

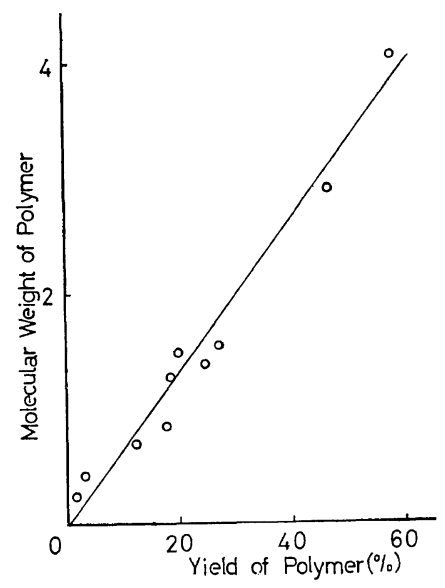

Figure 2. Molecular weight of poly-THF vs. yield of polymer. during the the course of the polymerization (Table I). These results indicate that a living polymer of THF is formed in the electrolytic polymerization.

In order to elucidate the relationship between the amount of current and the number of the propagating end formed in the electrochemical process, kinetic studies have been carried out. If it could be assumed that initiation is fast as compared with propagation at $30^{\circ} \mathrm{C}$ and an equilibrium polymerization without termination proceeds by this system, the reaction rate is given by

$$
-\mathrm{d}[\mathrm{M}] / \mathrm{d} t=k_{p}\left[\mathrm{P}^{*}\right]\left([\mathrm{M}]-[\mathrm{M}]_{e}\right)
$$

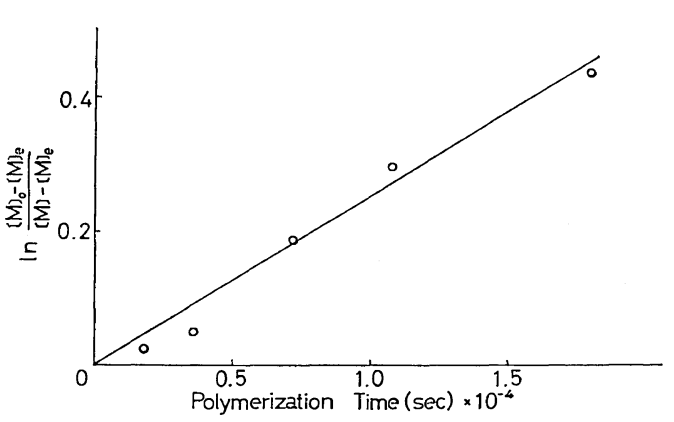

Figure 3. First order plots of the electrolytic polymerization of THF. Electrolysis conditions are shown in Table I (a).

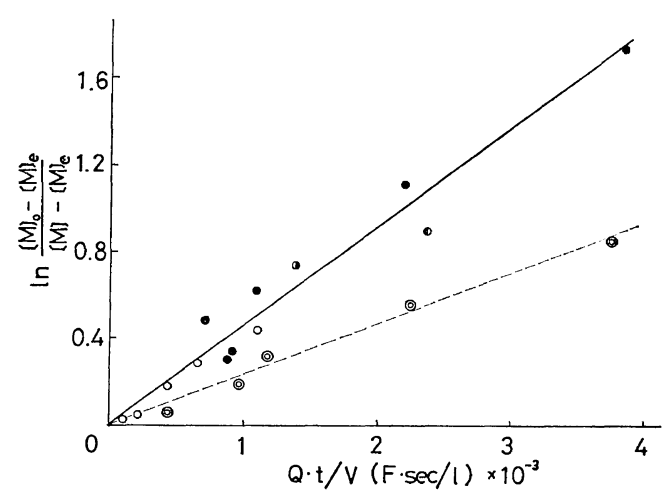

Figure 4. Effect of the amount of current and current density on the rate of the electrolytic polymerization of THF. Electrolysis conditions are are shown in Table I (a), except the amount of current and current density: $0.16 \mathrm{mF}, 1 \mathrm{~mA} / \mathrm{cm}^{2}$; D, $0.30 \mathrm{mF}, 1 \mathrm{~mA} / \mathrm{cm}^{2} ; \bullet, 1.2 \mathrm{mF}, 1 \mathrm{~mA} / \mathrm{cm}^{2} ; \bigcirc$, $3.7 \mathrm{mF}, 1 \mathrm{~mA} / \mathrm{cm}^{2}$; $\bigcirc, 0.75 \mathrm{mF}, 0.5 \mathrm{~mA} / \mathrm{cm}^{2}$. 
or

$$
\ln \frac{[\mathrm{M}]_{0}-[\mathrm{M}]_{e}}{[\mathrm{M}]-[\mathrm{M}]_{e}}=k_{p}\left[\mathrm{P}^{*}\right] t
$$

Plotting $\ln \left([\mathrm{M}]_{0}-[\mathrm{M}]_{e}\right) /\left([\mathrm{M}]-[\mathrm{M}]_{e}\right)$ against polymerization time, $t$, yielded a straight line as shown in Figure 3. On the assumption that one active species is formed by one electron oxidation, the concentration of the propagating end, $\left[\mathrm{P}^{*}\right]$, is written as

$$
\left[\mathrm{P}^{*}\right]=f \cdot \frac{Q}{V}
$$

where $f$ is the current efficiency; $Q$, the amount of current; $V$, the volume of the system. Substituting the above expression for $\left[\mathrm{P}^{*}\right]$ in eq 2 yields eq 4:

$$
\ln \frac{\left[\mathrm{M}\left[{ }_{0}-\right] \mathrm{M}\right]_{e}}{[\mathrm{M}]-[\mathrm{M}]_{e}}=\left(k_{p} \cdot f\right)\left(Q \cdot \frac{t}{V}\right)
$$

As shown in Figure 4, a straight line was obtained by plotting $\ln \left([\mathrm{M}]_{0}-[\mathrm{M}]_{e}\right) /\left([\mathrm{M}]-[\mathrm{M}]_{e}\right)$ vs. $Q(t / V)$. Consequently the current efficiency was almost independent of the amount of current within a range of $0.16 \sim 3.7 \mathrm{mF}$ and seemed to increase with increasing current density. These results suggest that the number of the propagating end is proportional to the number of electrons transferred in the electrolysis as shown in eq 3.

In an attempt to evaluate the anodic reaction and the initiation process, the polarograms of TEF were measured with $\mathrm{Bu}_{4} \mathrm{NClO}_{4}$ as an electrolyte, and compared with some vinyl monomers by means of the oscillopolarographic method. In dichloroethane or nitrobenzene, the

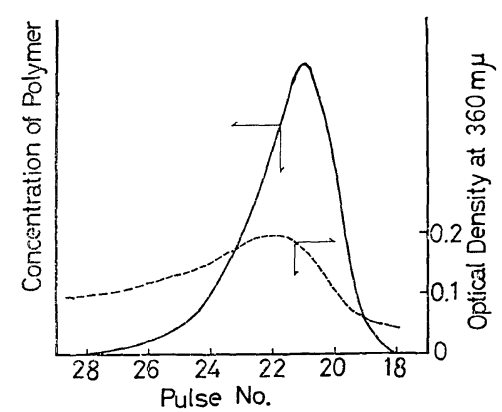

Figure 5. The gel-permeation chromatogram of the poly-THF (No. 135) and the optical density of the eluted fractions: solvent, THF, flow rate, $1.0 \mathrm{ml} / \mathrm{min}$ (See also Table III). oxidation waves were observed with a microplatinum electrode in a range of $1.4-1.9 \mathrm{~V} \mathrm{vs}$. Pt electrode for styrene, $\alpha$-methylstyrene, butadiene, isobutyl vinyl ether, isoprene, and isobutene, but not for $\mathrm{THF}^{5}$. Therefore, the direct transfer of an electron from a THF molecule on the anode is most unlikely in the reaction system. A possible explanation of the anodic reaction is shown as follows

$$
\mathrm{ClO}_{4}^{-}-\mathrm{CH} \rightarrow \mathrm{ClO}_{4} \text {. }
$$

The perchlorate ion is oxidized on the anode to a perchlorate radical (eq 5), which had been suggested by Maki. ${ }^{6}$ The formation of the radical has been also supported by the copolymerization study of methyl methacrylate with acrylonitrile in the anodic compartment, which will be described later. The perchlorate radical abstracts a hydrogen atom from a THF molecule to form a tetrahydrofuryl radical $I$ and a perchloric acid (eq 6), which actually initiates the polymerization of THF (eq 7). The radical I might be further oxidized by another perchlorate radical to form the cation II as follows, which was reported not to initiate the polymerization $^{7}$. It was also reported that polymerization of THF catalyzed by trityl salts were characterized by a dark color and the colored polymer was formed from dehydrofuran or furan $^{7}$. As the color change of the anolyte was similar to that of polymerization catalyzed by trityl salts, it might be suggested that dehydrofuran was formed from II by loss of a proton.

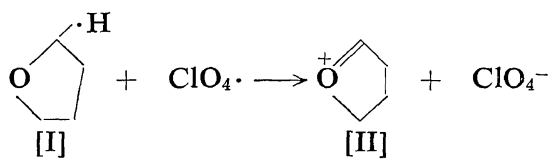

In order to confirm this mechanism (eq 5-8), the following three experiments were carried out; 
(1) On the assumption that the polymerization is initiated with perchloric acid and is terminated by water, a polymer should have two hydroxyl groups at both ends. An hydroxyl group in the poly-THF, which was electrolytically obtained, was determined by using phosgene $^{8}$. As shown in Table II, the content of the hydroxyl group determined here agrees approximately with the calculated value.

(2) If the cation II in eq 9 could initiate the polymerization, the polymer might have an aldehyde or acetal end group as follows ${ }^{9}$

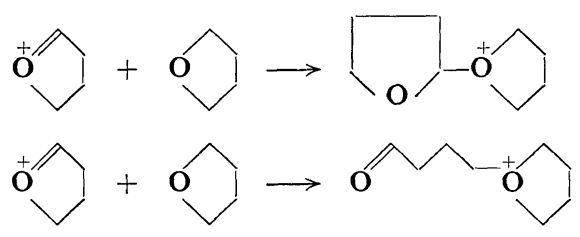

An aldehyde group in poly-THF which reacted with the hydrazine to produce the hydrazone, was determined by means of spectroscopy after the polymer was fractionated with gel-permeation chromatography. Only a few percent of the poly-THF were determined to have aldehyde groups (Table III). At this stage, it could not be confirmed whether aldehyde groups in the polymer were formed through the reaction 11 or by some other reaction.

(3) Meerwein reported that only liquid polyTHF was produced with perchloric acid ${ }^{10}$. However, the present study showed that when water

Table IV. The polymerization of THF with perchloric acid

\begin{tabular}{ccccl}
\hline No. & $\begin{array}{c}\text { THF in } \\
\text { feed, } \\
\text { g }\end{array}$ & $\begin{array}{c}\text { Reaction } \\
\text { time, } \\
\text { hr }\end{array}$ & $\begin{array}{c}\text { Yield of } \\
\text { polymer, } \\
\%\end{array}$ & $\begin{array}{l}\text { Molecular } \\
\text { weight of } \\
\text { polymer }\end{array}$ \\
\hline 1 & 3.83 & 16 & 6.0 & $0.7 \times 10^{4}$ \\
2 & 7.22 & 20 & 8.7 & 0.8 \\
3 & 6.02 & 28 & 15 & 1.8 \\
4 & 4.07 & 65 & 30 & 2.7 \\
5 & 3.46 & 116 & 49 & 2.2 \\
6 & 7.07 & 185 & 62 & 4.3 \\
\hline
\end{tabular}

a Polymerized at $30^{\circ} \mathrm{C}$. The reaction mixture $\left(\mathrm{THF}-\mathrm{HClO}_{4}\right)$ was separated into six portions. Each portion was treated with excess water after the required time.

b Estimated from the gel-permeation chromatogram. was rigorously removed from the $\mathrm{THF}-\mathrm{HClO}_{4}$ system, high molecular weight polymer was found to have been obtained. The yield and molecular weight of the polymer increased with the reaction time as shown in Table IV. These results are similar to that of the electrolytic polymerization of THF described in this paper.

As mentioned above, the initiation of the electrolytic polymerization of THF was assumed to involve radical species. ESR measurements were carried out on the anolyte to detect the presence of the radical species. However no signal has yet been observed. A perchlorate radical and a tetrahydrofuryl radical I may be too unstable to be detected under these conditions. The presence of the radicals can be confirmed from an electrolytic copolymerization study of methyl methacrylate and acrylonitrile by using $\mathrm{Bu}_{4} \mathrm{NClO}_{4}$ as a supporting electrolyte. After electrolysis, the catholyte and anolyte were treated separately with a methanol-water mixture. The results are summarized in Table V. The cathodic copolymer was rich in acrylonitrile, as was observed in the copolymer

Table V. The electrolytic copolymerization of methyl methacrylate and acrylonitrile in bulka

\begin{tabular}{|c|c|c|c|}
\hline & $\begin{array}{l}\text { Color of } \\
\text { copolymer }\end{array}$ & $\underset{\%}{\text { Yield, }}$ & $\begin{array}{c}\text { Content of b } \\
\text { acrylonitrile } \\
\text { unit, } \%\end{array}$ \\
\hline Anodic copolymer & White & 0.9 & 34 \\
\hline Cathodic copolymer & Yellow & 5.0 & 95 \\
\hline
\end{tabular}

a Monomers, methyl methacrylate, 0.36 mole; acrylonitrile, 0.36 mole; supporting electrolyte, $\mathrm{Bu}_{4-}$ $\mathrm{NClO}_{4}(2.06 \mathrm{~g})$; amount of current, $12 \mathrm{mF}$; electrolysis temperature, room temperature.

b Estimated from the nitrogen content of the polymer.

produced through the anionic propagation. In the anodic copolymer, the composition of the monomer units was similar to the one obtained with a radical initiator. Neither methyl methacrylate nor acrylonitrile is oxidized to form radicals in the anodic reaction, because these monomers do not give oxidation waves in polarographic measurements. Hence, the oxidized species at the anode might be a perchlorate radical or related radicals, as was estimated 
in the electrolytic polymerization of THF. The perchlorate end group of the copolymer could not be detected from the infrared spectrum.

In conclusion, the electrolytic polymerization of THF is initiated through the reaction of THF and the proton which is formed via hydrogen abstraction of a perchlorate radical (eq 6). Presumably the cation II is not an initiator, as was reported by Dreyfuss, et $a l^{7}$.

\section{REFERENCES}

1. H. Gilch and D. Michael, Makromol. Chem., 99, 103 (1966).

2. N. Yamazaki, Adv. Polym. Sci., 6, 377 (1969).

3. C. F. Heins, Polym. Letters, 7, 625 (1969).
4. M. P. Dreyfuss and P. Dreyfuss, J. Polym. Sci., Part A-1, 4, 2179 (1966).

5. N. Yamazaki, S. Hino, and S. Nakahama, unpublished data.

6. A. H. Maki and D. H. Geske, J. Chem. Phys., 30, 1356 (1959).

7. M. P. Dreyfuss, J.C. Westfahl, and P. Dreyfuss, Macromolecules, 1, 437 (1968).

8. D. G. Bush, L. J. Kunzelsauer, and S. H. Merrill, Anal. Chem., 35, 1250 (1963).

9. A. Ledwith and C. Fitzsimmonds, "Polymer Chemistry of Sysnthetic Elastomers, Part 1," High Polymers, Vol. XXIII, J. P. Kennedy and E.G.M. Törnqvist, Ed., Interscience Publishers, New York, N. Y., 1968, p 394.

10. H. Meerwein, D. Delfs, and H. Morschel, Angew. Chem., 72, 927 (1960). 